\title{
Mechanical Properties of Epoxy/Multi-Walled CARBON NANOTUBES COMPOSITES
}

\author{
Ivana Ropuša ${ }^{\mathrm{a}}$, Gianluca Carcia ${ }^{\mathrm{b}}$, Mauro Giorcelli ${ }^{\mathrm{b}}$, Alberto Tagliaferro ${ }^{\mathrm{b}}$, \\ Tatjana Haramina ${ }^{c}$, Lidija Ćurkovićc \\ ${ }^{a}$ Energoatest zaštita d.o.o., Potočnjakova 4, 10000 Zagreb, Croatia \\ ${ }^{b}$ Politecnico di Torino, Corso Duca degli Abruzzi 24, 10129 Torino, Italy \\ ${ }^{c}$ Faculty of Mechanical Engineering and Naval Architecture, Ivana Lučića 5, 10000 Zagreb, Croatia
}

\begin{abstract}
In this paper, two types of multi-wall carbon nanotubes (MWCNTs) were dispersed into two different epoxy resins by high - shear mixing. Dispersion and homogenisation of nanofillers was analysed by Field Emission Scanning Electrone Microscopy (FESEM). Microhardness of epoxy/MWCNTs nanocomposites, as well as of neat epoxy resins, is measured by Vickers method. The evolution of nanocomposites microhardness values were studied in function of curing time taking in account the influence of two different epoxy matrix and MWCNTs. Asymptotic values were analysed and compared with those of pure epoxy resin.
\end{abstract}

Keywords: nanocomposite; epoxy; multi-walled carbon nanotubes; microhardness
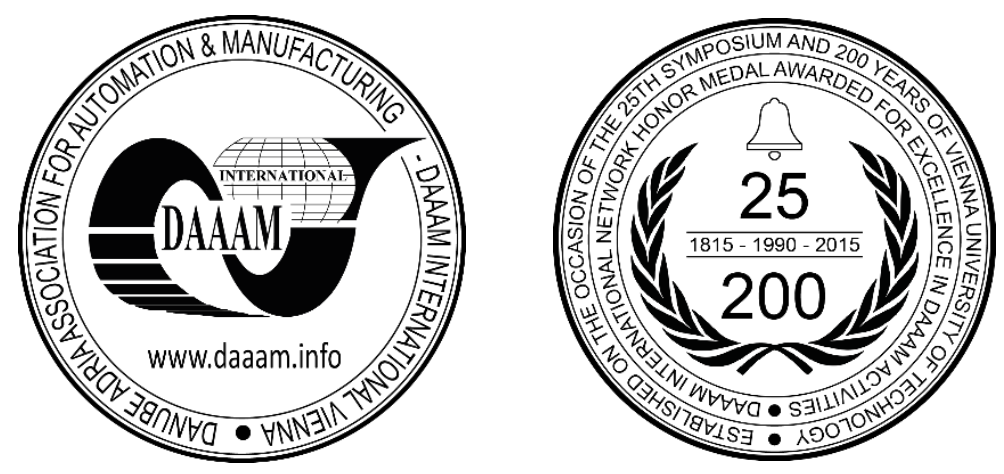

This Publication has to be referred as: Ropus, I[vana]; Carcia, G[ianluca]; Giorcelli, M[auro]; Tagliaferro, A[1berto]; Haramina, T[atjana] \& Curkovic, L[idija] (2016). Mechanical Properties of Epoxy/Multi-Walled Carbon Nanotubes Composites, Proceedings of the 26th DAAAM International Symposium, pp.0940-0947, B. Katalinic (Ed.), Published by DAAAM International, ISBN 978-3-902734-07-5, ISSN 1726-9679, Vienna, Austria DOI: $10.2507 / 26$ th.daaam.proceedings. 132 


\section{Introduction}

Polymers have a good combination of low density, good mechanical properties and extraordinary chemical stability. New technologies improve many of their properties including mechanical, electrical, barrier to oxygen and moisture properties etc.

Polymer composites consist of a polymer matrix in which a particular filler is dispersed. The aim is to transfer the filler properties to the matrix. Shapes and characteristics of filler have to be taken into account to reach this goal. Polymer nanocomposites are a new class of composites that are particle-filled polymers where at least one dimension of the dispersed particles is in the nanometer range [1]. Mixing procedure is an important step towards the creation of a deep adhesion between a filler and a polymer matrix. The properties of the filler are transferred by the contact between the two phases [2].

In last decades many studies of polymer based nanocomposites filled with carbon nanotubes (CNTs) were performed. Thus in [3] nanocomposite, polyamide 6 matrix filled with $0.5 \mathrm{wt}$ \% of CNTs, indicates that the used CNTs influence the glass transition and crystallization. Also, CNTs, that exhibit flexible-rod morphology, reduce mechanical property enhancement since the bending modulus controls the composite properties.

Ogaswara et al. [4] showed by dynamic mechanical analysis (DMA) that, MWCNTs dispersed in thermosetting polyimide TripleA PI, increase its glass transition temperature.

Furthermore, for polypropylene (PP) nanocomposites, in which polypropylene grafted maleic anhydride (PP-g-MA) was added to promote CNTs dispersion, Prashantha et al. [5] showed that tensile and bending moduli and strengths of nanocomposites increased comparing to neat epoxy resin.

Favorable mechanical properties of epoxy resins, such as good stiffness, considerable adhesion to the implanted fiber, specific strength, dimensional stability and chemical resistance, causes its broad appliance as matrix for structural composite materials, adhesives and organic coatings [6-9].

To achieve even better properties, epoxy resin matrices can be mixed with nanotubes. Carbon nanotubes (CNTs), an allotrope of Carbon composed of rolled layer of graphene, have very good electrical, thermal, optical, rheological and mechanical properties [10-16]. Considering these properties, polymer/CNTs nanocomposites usage in a wide spectrum of industries like aerospace industry, marine, armor, civil engineering, automobile even sport industry can be foreseen [17-20].

Hsu et al. [21] assessed the mechanical properties of biphenyl liquid crystalline epoxy/CNTs composites. Vickers microhardness examination conducted with the loading force of $4.903 \mathrm{~N}$ and loading time of $10 \mathrm{~s}$ were carried out on six different amounts of ef-CNT (0.0, 0.5, 1.0, 2.0, 4.0, $10.0 \mathrm{wt}$. \%). The Vickers hardness of the neat epoxy resin was HV0.5 $=16.62 \mathrm{HV}$, whereas that of the composite with $2.00 \mathrm{wt}$ \% epoxy-functionalized CNTs (ef-CNTs) was $63 \%$ higher (27.14 HV).

Using $(0.1,0.2,0.5,1.0,1.5,2.0,2.5,3.0,3.5,4.0,4.5,5) \mathrm{wt} . \%$ of MWCNT as reinforcement in epoxy resin, Al-Rawi et al. [22], got Charpy impact strength and hardness by Vickers method highest at $1.5 \mathrm{wt}$. \%. Till that point, with increasing weight percentage, hardness and impact strength gradually increased but after $1.5 \mathrm{wt}$. \% values started slightly to decrease.

To fully exploit the reinforcing potential of nanotubes two critical issues should be tackled: (i) the dispersion of nanotubes in a polymer matrix and (ii) the interfacial bonding between the nanotubes and the polymer matrix. Weak interaction of nanotube bundles and aggregation would result in poor dispersion that significantly reduces the reinforcement effect [23].

Commonly used methods for improvement of dispersion of CNTs can be classified from three points of view: mechanical (ultrasonic dispersion, high - shear mixing), physical (adsorption and/or wrapping of polymers or surfactants to the surface of the CNTs) and chemical (covalent chemical bonding - grafting- of polymer chains to the CNT surfaces) [24].

In this work epoxy based composites were prepared by adding $1 \mathrm{wt}$. \% of multi-wall carbon nanotubes (MWCNTs) to the resin. Two different epoxy resins were used as host materials and mixed with two types of nanofillers. Neat epoxy resins, as well as MWCNTs and the nanocomposites were characterized by means of Field Emission Scanning Electrone Microscopy (FESEM) and by Vickers tests. The measured microhardness of the nanocomposites was compared to that of the respective solid neat epoxy resin.

\section{Materials and methods}

\subsection{Epoxy resins and nanocomposites}

Nanocomposites that will be discussed in this paper were prepared with two different types of epoxy resin (Nan Ya Epoxy Resins): (i) one epoxy resin, NPEF-164X is a diluted epoxy resin based on Bisphenol-A/Bisphenol-F diglycidyl ethers mixed with $\mathrm{C}_{12}-\mathrm{C}_{14}$ alkyl glycidyl ether reactive dilutent whose viscosity at $\mathrm{cps} / 25^{\circ} \mathrm{C}$ is $700-1100$ and the other, (ii) NPEK-114L is a diluted epoxy resin based on Bisphenol-A diglycidyl ether mixed with $\mathrm{C}_{12}-\mathrm{C}_{14}$ alkyl glycidyl ether with cps/ $25^{\circ} \mathrm{C}$ viscosity of $550-750$. The curing agent for both types of resins was cycloaliphatic amine hardener DCure 304 (Epocat Nederland bv).

To produce nanocomposites $1 \mathrm{wt}$. \% of two types of Nanothinx (Greece) multi-wall carbon nanotubes (MWCNTs - see Table 1 for their characteristics) were used as fillers. 


\begin{tabular}{lllll}
\hline Acronym & Labels & $\begin{array}{l}\text { Diameter D } \\
(\mathrm{nm})\end{array}$ & $\begin{array}{l}\text { Length } \\
(\mu \mathrm{m})\end{array}$ & $\begin{array}{l}\text { Purity } \\
(\text { weight \%) }\end{array}$ \\
\hline MW6 & NTX-1 & $15-35$ & $\geq 10$ & 97 \\
MW7 & NTX-3 & $25-40$ & $\geq 10$ & $\leq 98.5$ \\
\hline
\end{tabular}

Table 1. Specifications of MWCNTs considered in this work

Steps of preparation the nanocomposites were the following.

- Pre-determined amounts of filler and epoxy resin were weighted and preliminary mixed together by hand.

- High - shear mixing method by Ultra turrax ${ }^{\circledR}\left(\mathrm{IKA}{ }^{\circledR}\right.$ - Werke GmbH \& Co. KG, Staufen, Germany) was used for 2 min to achieve well dispersed solution. Ultra turrax ${ }^{\circledR}$ (range from 3,000 to 25,000 rpm) is based on extremely strong shear forces between a rotor within stationary stator which results in very well dispersion.

- A curing agent (D-Cure 304) was added to the mixture in 100:60 ratio with respect to epoxy resin and then stirred mechanically for 10 minutes. The mixture was slowly poured into cylindrical molds trying to avoid inclusion of the air in material while pouring

- The nanocomposites were subsequently degassed in a vacuum chamber as follows: sample 1 and 2 for 10 minutes and samples 3, 4 for $30 \mathrm{~min}$. Prepared samples, after they were left $24 \mathrm{~h}$ in ambient air, were post cured in an oven in four successive curing sessions: (i) 3 hours at $80{ }^{\circ} \mathrm{C}$; (ii) $4 \mathrm{~h}$ at $100{ }^{\circ} \mathrm{C}$, (iii) $5 \mathrm{~h}$ at $100{ }^{\circ} \mathrm{C}$ and (iv) $5 \mathrm{~h}$ at $100{ }^{\circ} \mathrm{C}$.

Preparation procedure of the nanocomposites was the same for all samples whose composition can be seen in the Table 2.

\begin{tabular}{cccc}
\hline Acronym & Resin & wt. \% & MWCNTs \\
\hline Sample 1 & NPEF-164X & 1 & MW6 \\
Sample 2 & NPEK-114L & 1 & MW6 \\
Sample 3 & NPEF-164X & 1 & MW7 \\
Sample 4 & NPEK-114L & 1 & MW7 \\
Sample 5 & NPEK-114L & - & - \\
Sample 6 & NPEF-164X & - & - \\
\hline
\end{tabular}

Table 2. Composition of epoxy/MWCNTs used

\subsection{FESEM analysis}

ZEISS SUPRA $^{\mathrm{TM}} 40$ FESEM was used in order to investigate the morphology of nanocomposites. It is a high vacuum instrument (pressure below $1 \times 10^{-7} \mathrm{~Pa}$ in the gun zone) that has a magnification in the range of 12 up to 900.000 times and a working distance ranging from 1 to $50 \mathrm{~mm}$. Field emission cathode in the electron gun feeds the Field Emission Gun used in this FESEM and has spatial resolution $<2 \mathrm{~nm}$ [25].

Samples have been crio-fractured in order to have access to internal surfaces and check the structure of the composites. Crio-fracture brings samples under the glass transition temperature so that the inner surface is made accessible without any modifications. The observation of dielectric material through FESEM is limited by the "Charge-Up" phenomenon, which is an accumulation of charge on the surface of the material. This act as a barrier against the electrons coming from the electronic gun of the microscope, worsening its resolution. In order to solve this problem caused by dielectric nature of polymer based composites, all the samples were coated by a nanometric chromium layer.

All samples were prepared for FESEM in the same way and observed in the same session after curing $24 \mathrm{~h}$ on ambient air.

\subsection{Vickers microhardness measurement}

The hardness of all samples was measured under ambient laboratory conditions using a micro-hardness tester, an Instron, Wilson-Wolpert Tukon 2100B. Vickers hardness measurements HV0.1 were performed using an indentation load of $0.9807 \mathrm{~N}$ for $10 \mathrm{~s}$.

The average value of diagonal lengths of the indentation for each load was used to calculate the hardness according to Eq. (1).

$$
H V=\alpha \frac{F}{d^{2}}
$$


Where F stands for applied load $(\mathrm{N}), d(\mathrm{~mm})$ is the mean length of the indentation diagonals $\left(d=\frac{d_{1}+d_{2}}{2}\right)$, while $\alpha$ is the indenter's geometrical constant, which equals 0.1891 for the Vickers diamond pyramid.

Hardness of each sample was determined from the average value of 10 indentations.

\section{Result and discussion}

\subsection{FESEM characterization}

\subsubsection{Resins analysis}

Morphology of resins used in this research after $24 \mathrm{~h}$ curing in ambient air was investigated by FESEM. In Figure 1A the surface of the resin NPEF-164X is shown. Observed surface has linear and sharp defined stripes.

Figure 1B represents the micrography of the NPEK-114L resin. There are not any regular, parallel lines but only irregular shapes that might be caused by lower viscosity then resin NPEF-164X.

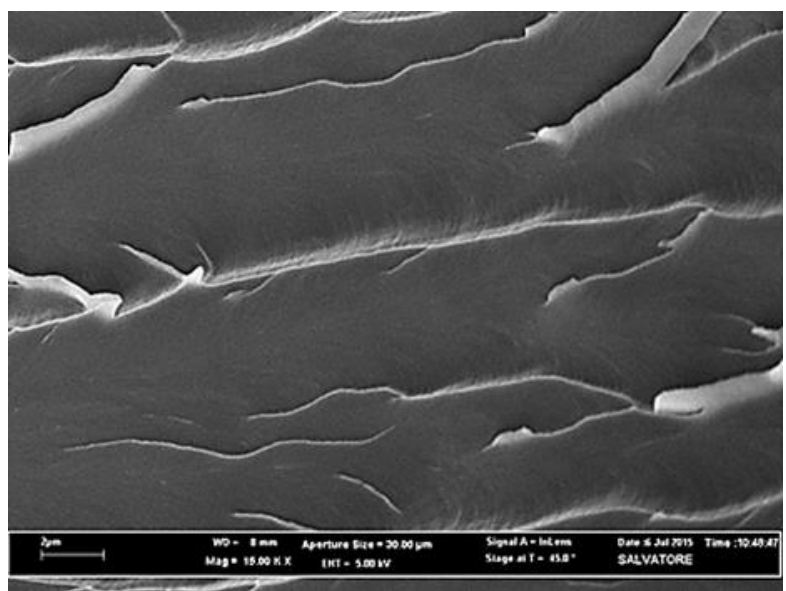

A

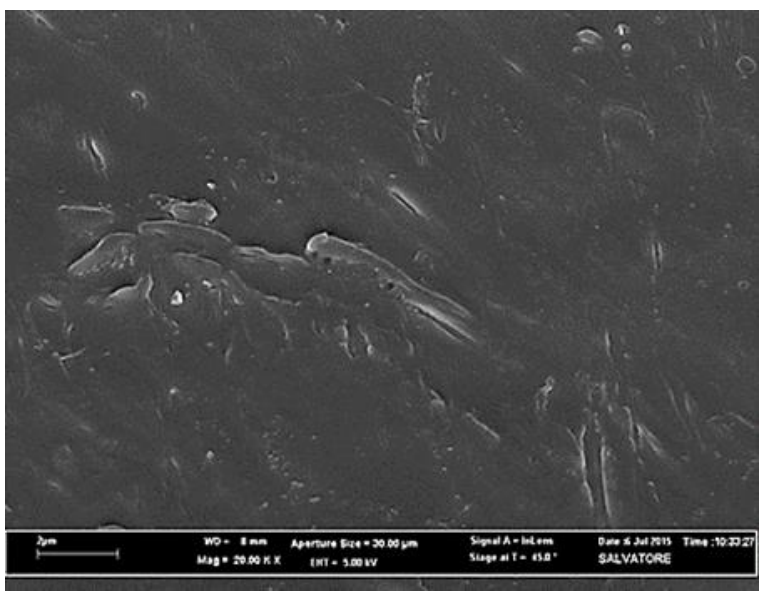

B

Fig. 1. (A) NPEF-164X neat resin; (B) NPEK-114L neat resin

\subsubsection{Multi - walled carbon nanotubes analysis}

A comparison of different kinds of nanotubes is shown in Figures 2A and 2B.

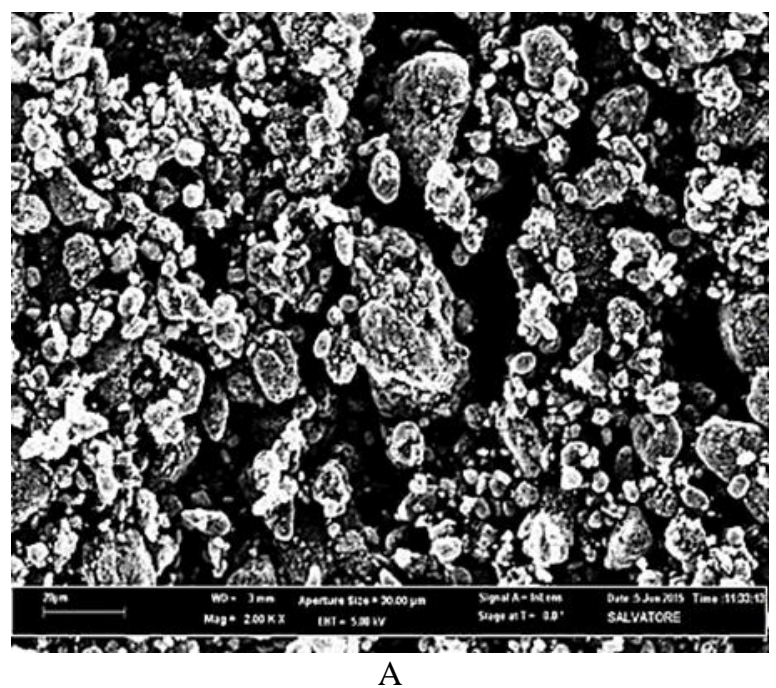

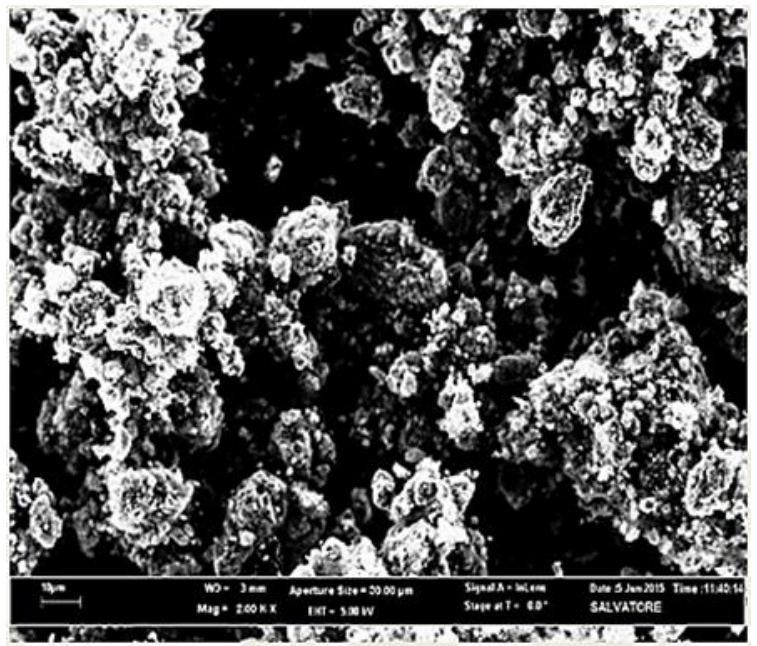

B

Fig. 2. (A) pure MW6; (B) pure MW7

Looking at neat MWCNTs used in this paper it seems that the thicker MW7 nanotubes (Figure 2B) were more closely packed than the thinner MW6 (Figure 2A). In the case of MW6 one can easily recognize different spots corresponding to different CNT while in the other picture, agglomerates mainly prevail. 
For the MW6 (Figure 3A) and for MW7 (Figure 3B), one can notice that both, the wider and the narrow nanotubes, are present. Diameters are close to the values reported in the datasheet (Figures $3 \mathrm{~A}$ and $3 \mathrm{~B}$ ).

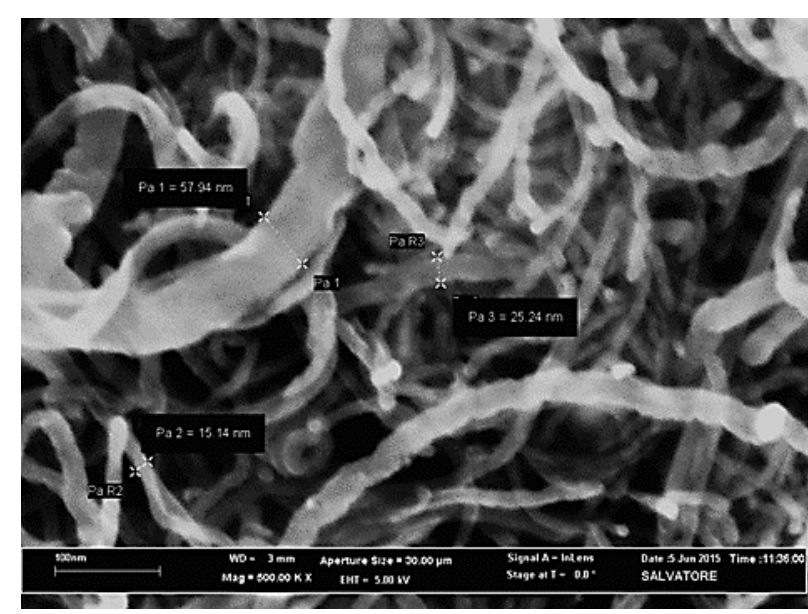

A

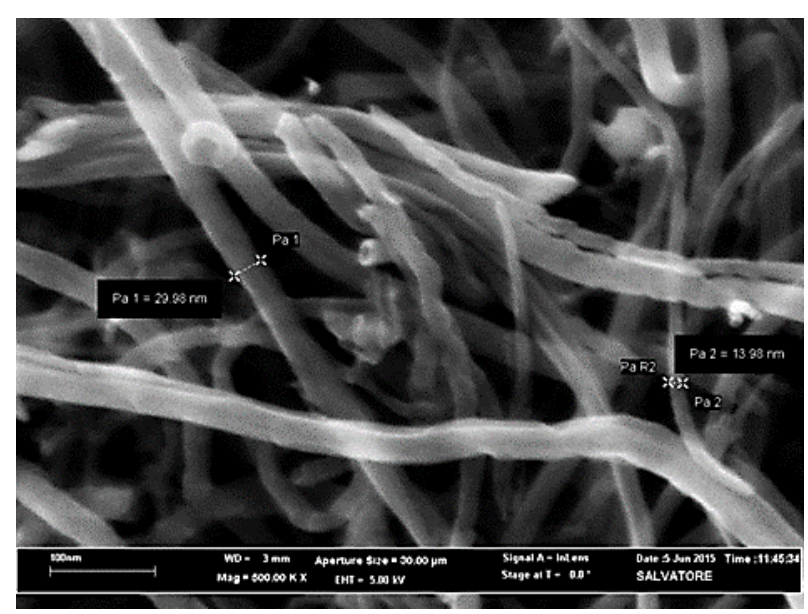

B

Fig. 3. (A) pure MW6; (B) pure MW7

\subsubsection{Nanocomposites analysis.}

A dispersion comparison of four samples prepared with two different kinds of nanotubes (MW6 and MW7 1 wt. $\%$ ) and resins (NPEF-164X and NPEK-114L) will be discussed in this section.

As shown in Figures 4A and 4B, due to the mixing mechanism (Ultra turrax ${ }^{\circledR}$ ), one can say that multi-walled carbon nanotubes are present in the whole polymer matrix volume even though there are some regions in which agglomerates and holes are visible, especially in the sample 1. The origin of the holes might be in the air bubbles trapped during the preparation of nanocomposites.

One can notice that MW7 nanotubes in Figures 5A and 5B more arranged surface lines are visible with less agglomerates and more parallel arranged fillers. The reason for that might be a bigger diameter of MW7 than MW6 carbon nanotubes.

Considering the dispersion of fillers in matrices smaller agglomerates are found in the resin with smaller viscosity and that is the resin NPEK-114L.

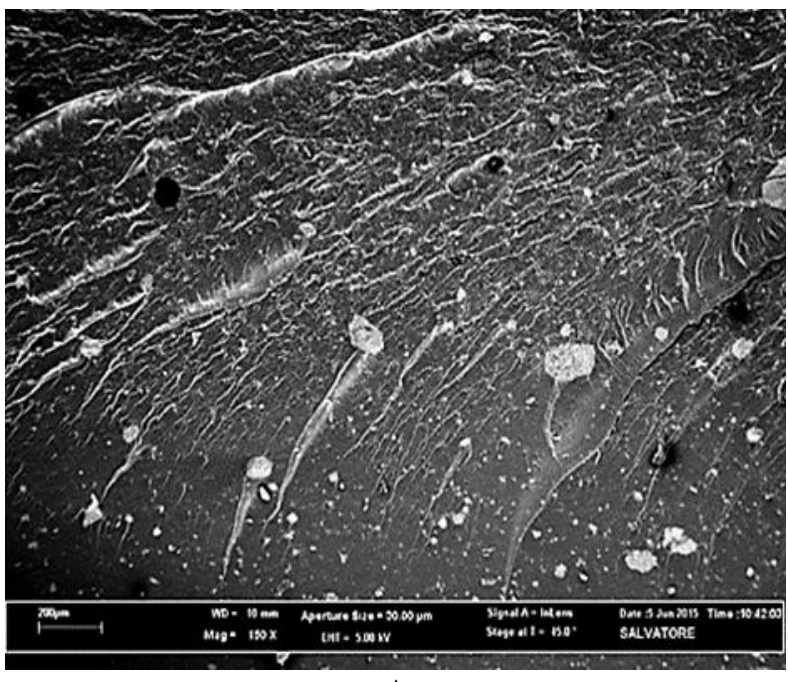

A

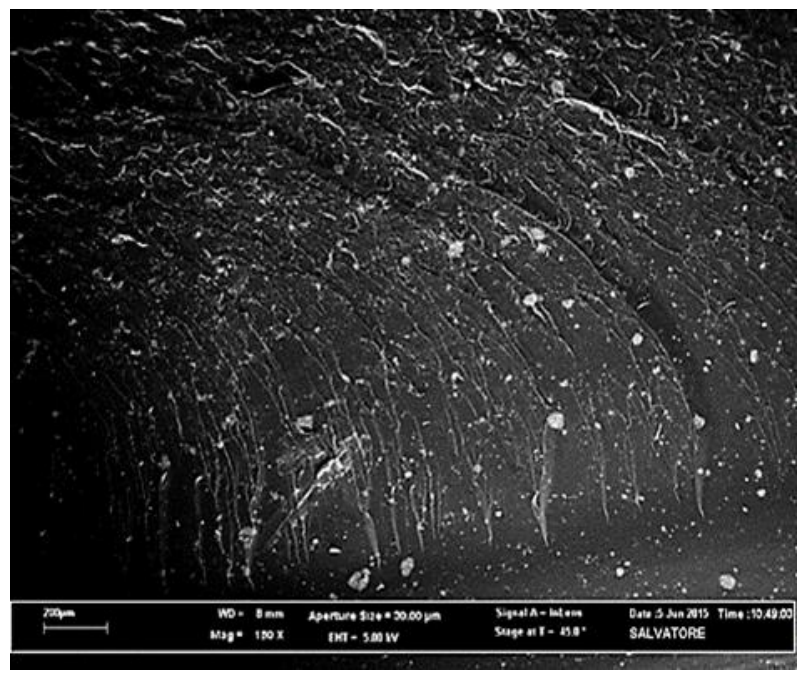

B

Fig. 4. (A) sample 1 (resin NPEF-164X + MW6 1 wt. \%); (B) sample 2 (resin NPEK-114L + MW6 1 wt. \%) 


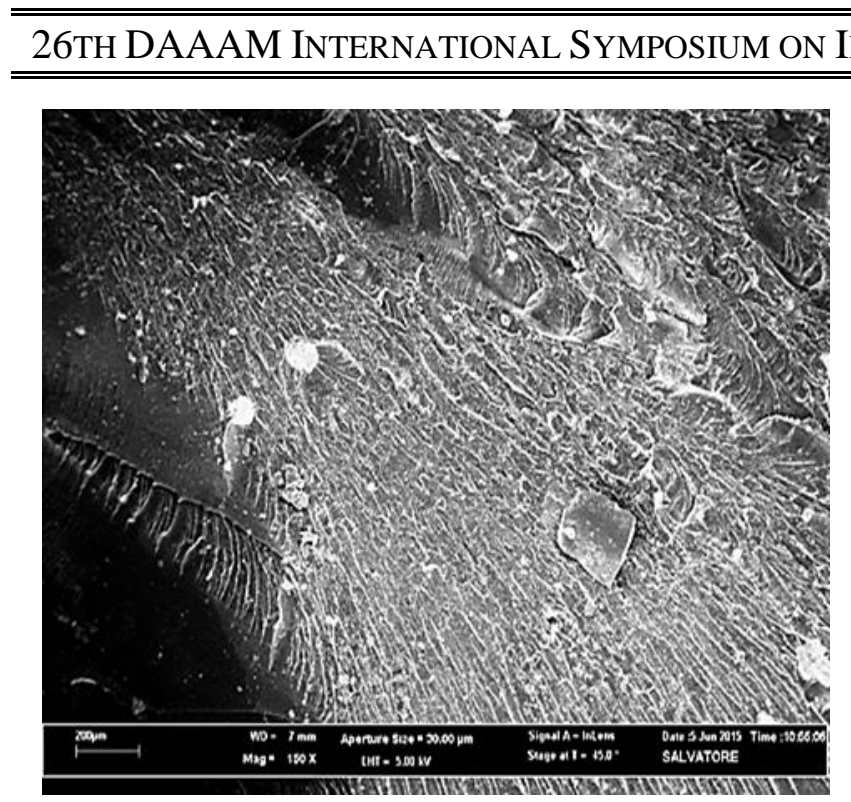

A

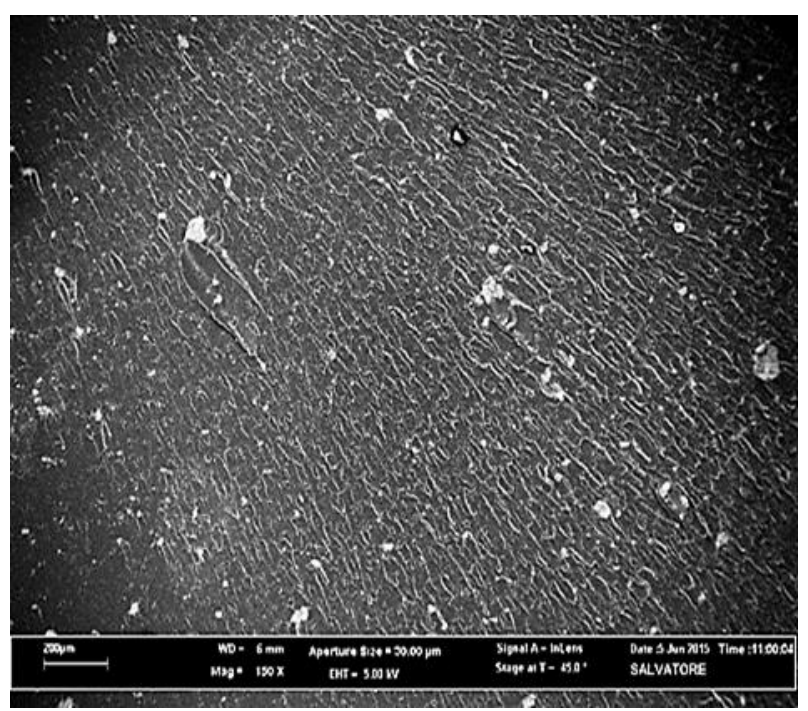

B

Fig. 5. (A) sample 3 (resin NPEF-164X + MW7 1 wt. \%); (B) sample 4 (resin NPEK-114L + MW7 1 wt. \%)

\subsection{Vickers microhardness}

The Vickers microhardness was calculated according to the Eq. (1). The tests were performed in all stages of the curing procedure. In that way changes in hardness were observed for neat resins, as well as those of nanocomposites.

The producer's curing recommendation was optional curing in oven for 60 min on $50-60{ }^{\circ} \mathrm{C}$.

There is a large variety in curing times and temperatures used for epoxy/CNTs nanocomposite preparation in literature, from the samples cured only in ambient air [26] to those cured for e.g. $24 \mathrm{~h}$ for $60{ }^{\circ} \mathrm{C}$ [27].

In this research four post curing sessions were obtained. In the meantime, after each curing session, microhardness measurements were performed.

Results by stages, averages of ten values with its standard deviations are shown in Table 3.

\begin{tabular}{l|cccccc}
\hline \multirow{3}{*}{$t, \mathrm{~h}$} & \multicolumn{5}{|c}{$H V 0.1$} \\
\cline { 2 - 7 } & $\begin{array}{c}\text { NPEF-164X/ } \\
\text { MW6 }\end{array}$ & $\begin{array}{c}\text { NPEK-114L/ } \\
\text { MW6 }\end{array}$ & $\begin{array}{c}\text { NPEF-164X/ } \\
\text { MW7 }\end{array}$ & $\begin{array}{c}\text { NPEK-114L/ } \\
\text { MW7 }\end{array}$ & NPEK-114L & NPEF-164X \\
\hline 0 & $5.47 \pm 0.14$ & $5.45 \pm 0.19$ & $8.71 \pm 0.04$ & $6.93 \pm 0.16$ & $8.65 \pm 0.09$ & $8.49 \pm 0.73$ \\
3 & $13.86 \pm 0.18$ & $12.81 \pm 0.47$ & $15.14 \pm 0.23$ & $13.43 \pm 0.16$ & $14.12 \pm 0.77$ & $14.45 \pm 0.70$ \\
7 & $17.79 \pm 0.83$ & $18.47 \pm 0.72$ & $19.35 \pm 0.36$ & $17.90 \pm 0.07$ & $19.34 \pm 0.99$ & $18.97 \pm 0.26$ \\
12 & $21.68 \pm 0.53$ & $23.91 \pm 0.10$ & $21.47 \pm 0.36$ & $20.19 \pm 0.06$ & $20.01 \pm 0.04$ & $19.59 \pm 0.37$ \\
17 & $21.66 \pm 0.56$ & $23.96 \pm 0.02$ & $22.59 \pm 0.49$ & $20.62 \pm 0.71$ & $20.07 \pm 0.16$ & $20.25 \pm 0.03$ \\
\hline
\end{tabular}

Table 3. Vickers microhardness (average values and the standard deviation of 10 measurements) of the epoxy/MWCNTs nanocomposites as a function of the curing time.

Figure 6 represents the change in calculated hardness values of investigated samples as a function of the curing time.

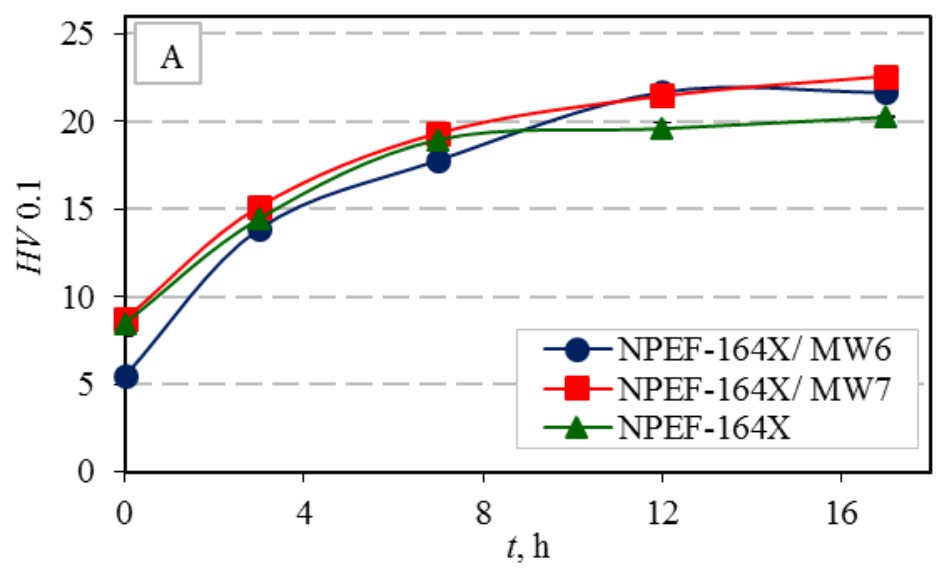

A 


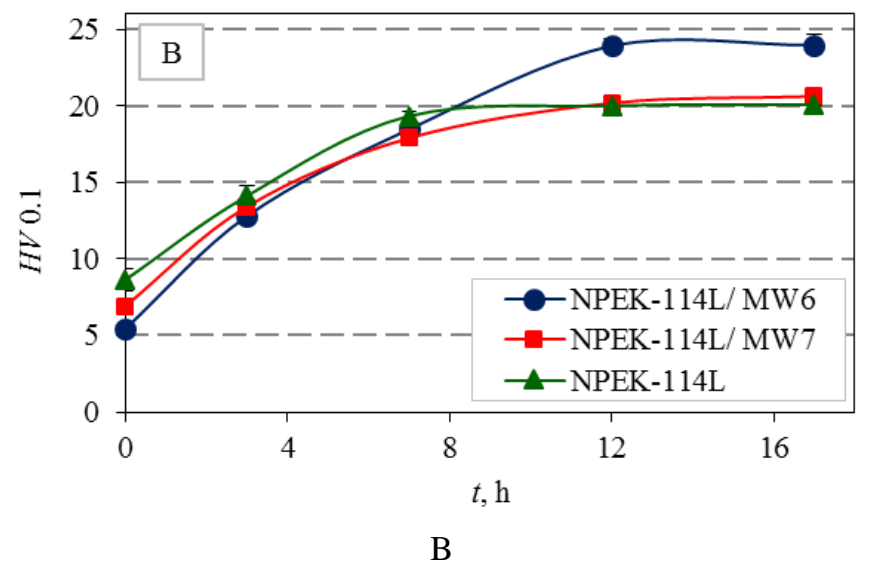

Fig. 6. Vickers microhardness of neat resins and nanocomposites as a function of the curing time.

Microhardness of samples was measured after initial preparation, after $24 \mathrm{~h}$ of curing at room temperature, without post curing treatment. As it can be seen, there was no significant difference between hardness values of neat resins and nanocomposites. Microhardness values of the nanocomposites were even lower than that of neat resin, except for sample 3 that was a bit higher. The same behavior was observed after the first and the second heating. After the third stage nanocomposites achieved higher hardness values than those of the neat resins. After $12 \mathrm{~h}$ of total curing time and the fourth curing period the hardness values changed negligible. Obtained results indicated that optimal curing time performed in this research for all samples was $12 \mathrm{~h}$. The first curing $\left(3 \mathrm{~h} / 80^{\circ} \mathrm{C}\right)$ doubled hardness of all samples. After the second curing step $\left(4 \mathrm{~h} / 100^{\circ} \mathrm{C}\right)$ hardness had an additional increase of about one third, while after the third stage $(5 \mathrm{~h} /$ $\left.100{ }^{\circ} \mathrm{C}\right)$ the obtained results increase just above $10 \%$. The last annealing $\left(5 \mathrm{~h} / 100^{\circ} \mathrm{C}\right)$ had for most samples a marginal effect. Altogether it can be said that microhardness increased from the initial to the fourth post curing interval approximately 3 times. The highest hardness values during the post curing treatment were shown by the composite made by NPEF-164X and MW7. However the final value reached by these samples was $22.5 \mathrm{HV}$ while the composite made by NPEK-114L and MW6 reached a final value of $24 \mathrm{HV}$ about $20 \%$ higher than values of neat resin. The hardness values obtained in this work are similar to those reported for similar epoxy /MWCNT systems [22].Besides the preparation and curing procedure, weight percent and types of carbon nanotubes have impact on hardness values [9, 22, 28 - 30]. Type of forces between atoms in material determines material's hardness [31]. The strong binding at the interface phases nano carbon and epoxy enhances the coherence of mixture [22].

\section{Conclusion}

Considering four types of nanocomposites prepared in this research, using two types of epoxy resins and two types of multi-wall carbon nanotubes it can be noticed that diameter of nanotubes has impact on formation of size of agglomerates.

The reason for that might be that thinner nanotubes, in this case MW6, at the same percentage are more in quantities compared with the thicker ones (MW7) and that's why more entangled.

Comparing agglomerates in both resins, before thermal treatment, it can be noticed that, the resin with lower viscosity has smaller agglomerates. In this case it is the resin NPEK-114L.

Generally, for all samples the highest increase of microhardness was noted after the first and second curing treatment. After $12 \mathrm{~h}$ of total curing time, changes of samples hardness are negligible. Similar values obtained after $12 \mathrm{~h}$ and $17 \mathrm{~h}$ of total curing time indicated that optimal curing time for these samples is $12 \mathrm{~h}$.

Since, in this paper, focus was on curing effect, other CNT filling loads were not used. Further work will be carried out in this direction to achieve further improvement in the hardness value of composites and to find out the optimum filling loads. From this point of view this work represents a starting point for further research aimed to maximize the hardness within these systems.

\section{Acknowledgements}

The authors would like to thank to: Oxipol, in the person of Dr. F. Angelozzi, for providing us epoxy resin NPEF164X and NPEK-114L, Nanothinx (Greece) for MWCNTs, Dr. Guastella Salvatore for FESEM analysis and Robin Kuhn for collaboration in production of nanocomposites.

\section{References}

[1] M. Alexandre, P. Dubois, Polymer-layered silicate nanocomposites: preparation, properties and uses of a new class of materials. Mater. Sci. Eng. 28 (2000) 1-63. 
[2] A. Kubacka, M.L. Cerrada, C. Serrano, M. Fernández-García, M. Ferrer, M. Fernández-Garc, Plasmonic nanoparticle/polymer nanocomposites with enhanced photocatalytic antimicrobial properties. J. Phys. Chem. 113 (2009) 9182-9190.

[3] C.G. Zhao, G.J. Hu, R. Justice, D.W. Schaefer, S. Zhang, M.S. Yang, C.C. Han, Synthesis and characterization of multi-walled carbon nanotubes reinforced polyamide 6 via in situ polymerization, Polymer 46 (2005)5125-5132.

[4] T. Ogasawara, Y. Ishida, T. Ishikawa, R. Yokota, Characterization of multi-walled carbon nano-tube/phenylethynyl terminated polyimide composites, Compos. Part A: Appl. Sci. Manuf. 35 (2004) 67-74.

[5] K. Prashantha, J. Soulestin, M.F. Lacrampe, M. Claes, G. Dupin, P. Krawczak, Multi-walled carbon nanotube filled polypropylene nanocomposites based on masterbatch route: Improvement of dispersion and mechanical properties through PP-g-MA addition, eXPRESS Polymer Letters 2 (2008) 735-745.

[6] F.J. Fisher, M.M. Salama, Emerging and potential composite applications for deepwater offshore operations. In: S.S. Wang, J.G. Williams, K.H. Lo, editors. Composite materials for offshore operations - 2. Houston, TX: American Bureau of Shipping (1999) 33-49.

[7] J.R. M. d'Almeida, R.C. de Almeida, W.R. de Lima, Effect of water absorption of the mechanical behavior of fiberglass pipes used for offshore service waters, Composite Structures 83 (2008) 221-225.

[8] J.B. Donnet, Nano and microcomposites of polymers elastomers and their reinforcement, Compos. Sci. Technol. 63 (2003) $1085-1088$.

[9] S. Bal1, S.S. Samal, U.K. Mohanty, Mechanical and Microstructural Analysis of Carbon nanotube Composites Pretreated at Different Temperatures, American Journal of Materials Science 1 (2011) 5-11.

[10] M.R. Saeb, F. Najafi, E. Bakhshandeh, H.A. Khonakdar, M. Mostafaiyan, F. Simon, C. Scheffler, E. Mäder, Highly curable epoxy/MWCNTs nanocomposites: An effective approach to functionalization of carbon nanotubes, Chemical Engineering Journal 259 (2015) 117-125.

[11] P. Pötschke, T.D. Fornes, D.R. Paul, Rheological behaviour of multiwalled carbon nanotube/polycarbonate composites, Polymer 43 (2002) 3247-3255.

[12] J.B. Donnet, Nano and microcomposites of polymers elastomers and their reinforcement, Compos. Sci. Technol. 63 (2003) 1085-1088.

[13] A. Chiolerio, M. Castellino, P. Jagdale, M. Giorcelli, S. Bianco, A. Tagliaferro, Electrical Properties of CNT-based Polymeric Matrix Nanocomposites, Carbon Nanotubes, Chepter 11 (2011) 215-230.

[14] S. Bal, Experimental study of mechanical and electrical properties of carbon nanofiber/ epoxy composites, Materials and Design 31 (2010) 2406-2413.

[15] M. Möhwald, A. Barz, J. Bliedtner, M. Schiling, C. Schiling, Activation of the Electrical Conductivity on NonConductive MWCNT-Filled Plastic Moldings by Laser Processing, Procedia Engineering 100 (2015) 1591-1597.

[16] M. Brcic, M. Canadija, J. Brnic, Influence of Waviness and Vacancy Defects on Carbon Nanotubes Properties, Procedia Engineering 100 (2015) 213-219.

[17] X. Chen, L. Zhang, M. Zheng, C. Park, X. Wang, C. Ke, Quantitative nanomechanical characterization of the van der Waals interfaces between carbon nanotubes and epoxy, Carbon 82 (2015) 214-228.

[18] P.M. Ajayan, J.M. Tour, Materials science - nanotube composites, Nature 447 (2007) 1066-1068.

[19] A.A. Koval'chuk, A.N. Shchegolikhin, V.G. Shevchenko, P.M. Nedorezova, A.N. Klyamkina, A.M. Aladyshev, Synthesis and properties of polypropylene/multiwall carbon nanotube composites, Macromolecules 41 (2008) 31493156.

[20] A. Dombovari, N. Halonen, A. Sapi, M. Szabo, G. Toth, J. Maklin, Moderate anisotropy in the electrical conductivity of bulk MWCNT/epoxy composites, Carbon 48 (2010) 1918-1925.

[21] S.H. Hsu, M.C. Wu, S. Chen, C.M. Chuang, H. Lin, W.F. Su, Synthesis morphology and physical properties of multi-walled carbon nano 7 tube/biphenyl liquid crystalline epoxy composites, Carbon 50 (2012) 896-905.

[22] K.R. Al-Rawi, A.J. Hedar, O.A. Mahmood, Effect Different Multi-Walled Carbon Nanotubes MWCNTs Type on Mechanical Properties of Epoxy Resin Nanocomposites, IJAIEM 3 (2014) 132-137.

[23] A. Kis, G. Csanyi, J.P. Salvetat, T.N. Lee, E. Couteau, A.J. Kulik, W. Benoit, J. Brugger, L. Forró, Reinforcement of single-walled carbon nanotube bundles by intertube bridging, Nat. Mater. 3 (2004) 153-157.

[24] F.L. Jin, S.J. Park, Recent Advances in Carbon-Nanotube-Based Epoxy Composites, Carbon Letters 14 (2013) 113.

[25] http://areeweb.polito.it/ricerca/carbongroup/fac_fesem.html

[26] K.T. Lau, S.Q. Shi, L.M. Zhou, H.M. Cheng, Micro-hardness and Flexural Properties of Randomly-oriented Carbon Nanotube Composites, Journal of Composite Materials February 37 (2003) 365-376.

[27] C.E. Pizzutto, J. Suave, J. Bertholdi, S.H. Pezzin, L.A.F. Coelho, S.C. Amico, Study of Epoxy/CNT Nanocomposites Prepared Via Dispersion in the Hardener, Materials Research 14 (2011) 256-263.

[28] J. Zhang, Y. C. Xu, P. Huang, Effect of cure cycle on curing process and hardness for epoxy resin, eXPRESS Polymer Letters 3, (2009) 534-541.

[29] E.P. Koumoulos, P. Jagdale, I.A. Kartsonakis, M. Giorcelli, A. Tagliaferro, C.A. Charitidis, Carbon Nanotube/Polymer Nanocomposites: A Study on Mechanical Integrity Through Nanoindentation, Polymer Composites 36 (2015), 1432-1446.

[30] G. Manjunatha, S. Rajesh., R. George, K. Naik, Influence of Post Heat Treatment Temperatures on Wear Properties of MWCNTs Reinforced Epoxy Composites, American Journal of Materials Science 5 (2015) 183-187.

[31] D. Bhattacharjee, J.F. Knott. Effect of mixed mode I and II loading on the fracture surface of polymethyl methacrylate (PMMA), Int. J. Fract. 72 (1995) 359-81. 